\title{
On Determination of Best-Possible Constants in Integral Inequalities Involving Derivatives
}

\author{
By Beny Neta
}

Abstract. This paper is concerned with the numerical approximation of the best possible constants $\gamma_{n, k}$ in the inequality

$$
\left\|F^{(k)}\right\|^{2} \leqslant \gamma_{n, k}^{-1}\left\{\|F\|^{2}+\left\|F^{(n)}\right\|^{2}\right\}
$$

where

$$
\|F\|^{2}=\int_{0}^{\infty}|F(x)|^{2} d x
$$

A list of all constants $\gamma_{n, k}$ for $n \leqslant 10$ is given.

1. Introduction. This paper utilizes the algorithm given in [1] to numerically approximate the best possible constants $\gamma_{n, k}, 1 \leqslant k<n$, for $n \leqslant 10$ in the inequality:

$$
\left\|F^{(k)}\right\|^{2} \leqslant \gamma_{n, k}^{-1}\left\{\|F\|^{2}+\left\|F^{(n)}\right\|^{2}\right\},
$$

where $\|\cdot\|$ denotes the $L_{2}[0, \infty)$ norm. The function $F$ has a locally absolutely continuous $(n-1)$ st derivative. The inequality (1) is equivalent to

$$
\left\|F^{(k)}\right\| \leqslant M_{n, k}\|F\|^{(n-k) / n}\left\|F^{(n)}\right\|^{k / n},
$$

where

$$
M_{n, k}^{2}=\gamma_{n, k}^{-1}\left(\frac{n-k}{k}\right)^{k / n}+\left(\frac{k}{n-k}\right)^{(n-k) / n}
$$

see [1].

Interest in inequalities (1) and (2) increased because of their close connection with problems of best approximation of the differentiation operator by bounded operators; see [2], [3] , [4] , [5], and with the problem of best approximation of one class of functions by another; see [4], [6], [7] .

In the next section we shall give lower and upper bounds for the best possible constants $\gamma_{n, k}$ and $M_{n, k}$ for $n \leqslant 10$.

2. Numerical Results. In this section the best possible constants $\gamma_{n, k}$ and $M_{n, k}$ are listed.

$$
\begin{gathered}
\gamma_{21}=1, \quad \text { see [1]. } \\
\gamma_{31}=\gamma_{32}=\sqrt[3]{3-2 \sqrt{2}}=.555669, \text { see }[1]
\end{gathered}
$$

Received October 31, 1978; revised February 1, 1980.

AMS (MOS) subject classifications (1970). Primary 46E30, 26A84; Secondary 47E05, $34 \mathrm{~B} 05,65 \mathrm{D} 20$. 
In [1],$\gamma_{41}$ is characterized as the smallest positive zero of the polynomial $Z^{8}-6 Z^{4}-$ $8 Z^{2}+1$, and $\gamma_{42}$ is the smallest positive zero of the polynomial $Z^{4}-2 Z^{2}-4 Z+1$. Using Müller's method [8], we obtain $\gamma_{41}=\gamma_{43}=.339246, \gamma_{42}=.225270$.

Remark. It is known, see [1], that

$$
\gamma_{n, n-k}=\gamma_{n, k} \text { for all } n, k \text {. }
$$

Using the algorithm in [1], one has the following table of lower and upper bounds on $\gamma_{n, k}$ for $2 \leqslant n \leqslant 10$ and $1 \leqslant k \leqslant[n / 2]$. For other values of $k$, use (4).

TABLE 1

$$
\gamma_{n, k} \text { for } 2 \leqslant n \leqslant 10,1 \leqslant k \leqslant[n / 2]
$$

\begin{tabular}{ccccc}
$n \backslash k$ & 1 & 2 & 3 & 4 \\
\hline 2 & 1. & & & \\
3 & .555669 & .225271 & & \\
4 & .339246 & $.0256, .102268)$ & & \\
4 & $(.225837, .2258375)$ & $(.102266)$ & & \\
5 & $(.160328, .160338)$ & $(.051986, .05199)$ & $(.0361167, .0361177)$ \\
6 & $(.11936, .11943)$ & $(.028924, .02895)$ & $(.014698, .0147)$ \\
7 & $(.09128, .09129)$ & $(.0172, .01723)$ & $(.0068112, .00681124)(.005014, .0050145)$ \\
8 & $(.07593, .07594)$ & $(.010795, .0108)$ & $(.00345, .0036)$ & $(.00193, .001938)$ \\
9 & $(.0479, .048)$ & $(.0068, .007)$ & $(.0014163, .0014165)(.000681505, .00068151)(.000642565, .00064257)$
\end{tabular}

Using (3) and the values listed in Table 1, one has the following table of lower and upper bounds on $M_{n, k}$ for $2 \leqslant n \leqslant 10$ and $1 \leqslant k \leqslant[n / 2]$. For other values of $k$, use $M_{n, n-k}=M_{n, k}$ for all $n, k$.

TABLE 2

\begin{tabular}{|c|c|c|c|c|c|c|}
\hline$n \backslash \mathbf{k}$ & & 1 & 2 & 3 & 4 & 5 \\
\hline 2 & 1.41421 & & & & & \\
\hline 3 & 2.07005 & & & & & \\
\hline 4 & 2.27432 & & 2.97963 & & & \\
\hline 5 & (2.70248, & $2.70249)$ & $(4.37797,4.37801)$ & & & \\
\hline 6 & (3.12838, & $3.12848)$ & $(6.02917,6.02940)$ & $(7.44141,7.44151)$ & & \\
\hline 7 & (3.55221, & $3.55325)$ & $(7.92662,7.93019)$ & $(11.60467,11.60546)$ & & \\
\hline 8 & (3.99579, & $3.99601)$ & $(10.09176,10.10056)$ & $(16.86722,16.86727)$ & $(19.97106,19.97206)$ & \\
\hline 9 & $(4.32029$ & $4.32057)$ & $(12.54043,12.54333)$ & $(23.07295,23.23717)$ & $(32.02543,32.09173)$ & \\
\hline 10 & (5.36995, & $5.37555)$ & $(15.35013,15.57423)$ & $(36.06112,36.06367)$ & $(53.62984,53.63004)$ & $(55.78980,55.79001)$ \\
\hline
\end{tabular}

$$
M_{n, k} \text { for } 2 \leqslant n \leqslant 10,1 \leqslant k \leqslant[n / 2]
$$

Remarks. 1. The lower and upper bounds for each $n$ and $k$ are given in parentheses and separated by a comma, for example, .11936 $\leqslant \gamma_{7,1} \leqslant .11943$.

2. The number $M_{4,2}$ in Table 2 agrees with that obtained by Bradley and Everitt [7].

3. The number $M_{6,3}$ in this table agrees with a result of Dawson and Everitt [9].

Conjecture. For fixed $k$ the $\gamma_{n, k}$ are decreasing functions of $n$. For fixed $n$ the $\gamma_{n, k}$ are decreasing functions of $k$ up to $k=[n / 2]$. 
Thus the initial value of $\gamma_{n, k}$ may be taken in the interval

$$
I_{n, k}^{*}=\left(0, \gamma_{n-1, k}\right) \text { for } n>2
$$

rather than the interval suggested by Kupcov, namely

$$
I_{n, k}=\left(0, g_{n, k}\right)
$$

where

$$
g_{n, k}=\frac{n}{k^{k / n}(n-k)^{(n-k) / n}}
$$

Acknowledgements. The author would like to thank Professors A. Zettl and M. K. Kwong for introducing him to the problem, and the referee for his suggestions which greatly improved the paper.

Department of Mathematical Sciences

Northern Illinois University

De Kalb, Illlinois 60115

1. N. P. KUPCOV, “Kolmogorov estimates for derivatives in $L_{2}[0, \infty)$," Proc. Steklov Inst. Math., v. 138, 1975, pp. 101-125.

2. S. B. STEČKIN, "Inequalities between norms of derivatives of arbitrary functions," Acta Sci. Math. (Szeged), v. 26, 1965, pp. 225-230.

3. S. B. STEČKIN, "Best approximation of linear operators," Mat. Zametki, v. 1, 1967, pp. 137-148 = Math. Notes, v. 1, 1967, pp. 91-99.

4. V. V. ARESTOV, "Sharp inequalities between the norms of functions and their derivatives," Acta Sci. Math. (Szeged), v. 33, 1972, pp. 243-267.

5. V. V. ARESTOV, "On some extremal problems for differentiable functions of one variable," Proc. Steklov Inst. Math., v. 138, 1975, pp. 1-29.

6. JU. N. SUBBOTIN \& L. V. TAIKOV, "Best approximation of a differentiation operator in the space $L_{2}$," Mat. Zametki, v. 3, 1968, pp. 157-164=Math. Notes, v. 3, 1968, pp. 100-105. 7. J. S. BRADLEY \& W. N. EVERITT, “On the inequality $\left\|f^{\prime \prime}\right\|^{2} \leqslant K\|f\| \cdot\left\|f^{(4)}\right\|, "$ Quart. J. Math. Oxford Ser. (2), v. 25, 1974, pp. 241-252.

8. S. D. CONTE \& C. DE BOOR, Elementary Numerical Analysis: An Algorithmic Approach, McGraw-Hill, New York, 1972.

9. E. R. DAWSON \& W. N. EVERITT, On Recent Results in Integral Inequalities Involving Derivatives, Lecture given at the Ordinary and Partial Differential Equations Conference held at Dundee, Scotland, March 1976. 